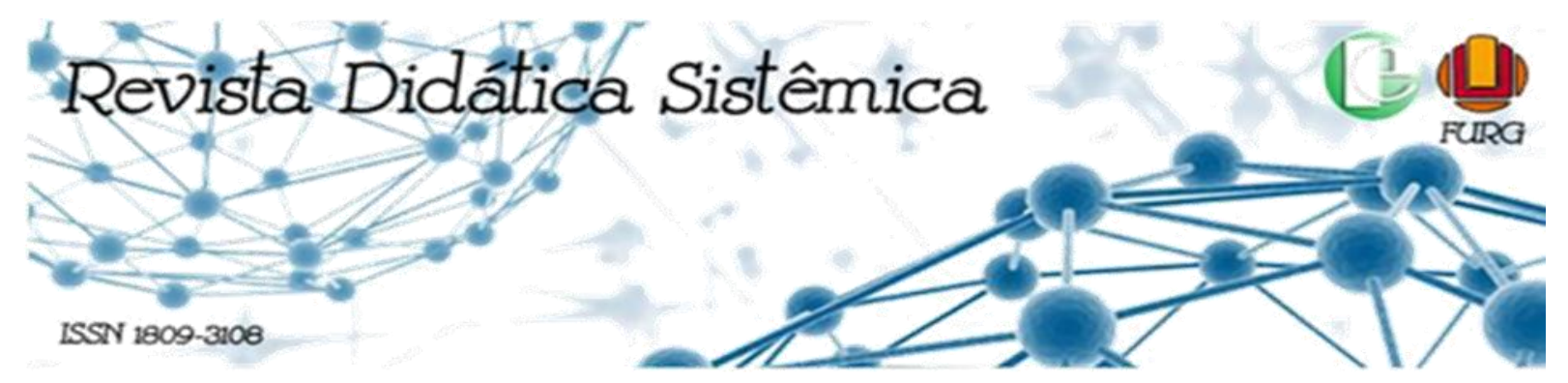

\title{
PROFESSORES DE EDUCAÇÃO FÍSICA \\ FRANQUEADOS A PROGRAMAS DE AULAS PRÉ-COREOGRAFADAS: MOTIVAÇÕES, RELAÇÕES COM A FORMAÇÃO INICIAL E ATUAÇÃO PROFISSIONAL
}

\author{
Elina Rodrigues de Oliveira* \\ Gustavo Freitas ${ }^{* *}$
}

\begin{abstract}
RESUMO
A expansão no número de academias de ginástica no Brasil provocou o surgimento de um novo produto no mercado fitness: as franquias de programas de aulas pré-coreografadas. Diante desse cenário, o artigo buscou identificar o que leva um professor de Educação Física a se tornar um franqueado, bem como discutir possíveis interfaces entre sua atuação profissional e a formação inicial. Entrevistas foram realizadas com cinco profissionais de Educação Física, com formação em licenciatura, afiliados a algum programa de aulas pré-coreografadas e atuantes com a modalidade no momento da pesquisa. Concluímos que as principais motivações para se tornar um franqueado são: o gosto pela dança, as experiências sociocorporais anteriores à formação inicial, o suporte e o marketing disponibilizados pela franquia. Concluímos que a adesão afeta a atuação profissional no sentido da responsabilização do indivíduo, por se manter atualizado e atuante no mercado, proporcionando-lhe uma vantagem competitiva em relação aos não-franqueados e possibilitando atender a um público-alvo que demanda por um determinado produto, no caso a modalidade vendida pela franquia.
\end{abstract}

Palavras-Chave: Programas de Ginástica. Ginástica de Academia. Formação Inicial. Educação Física.

\author{
PHYSICAL EDUCATION TEACHERS FRANCHISEES \\ TO PRE-CHOREOGRAPHED CLASS PROGRAMS: MOTIVATIONS, INTERACTIONS \\ WITH THE INITIAL TRAINING AND THE PROFESSIONAL PERFORMANCE
}

\begin{abstract}
The expansion in the number of fitness centers in Brazil caused the emergence of a new product in the fitness market: franchises of pre-choreographed classes programs. Given this scenario, this work sought to identify what leads Physical Education teachers to become a franchisee, as well as discuss possible interfaces between his professional performance and initial education. Interviews were conducted with five Physical Education professionals with training, franchisees to a pre-choreographed and active class program that were working at the time of the research. It was concluded that the main motivations for becoming a franchisee are personal taste in dance, such as socio-corporeal experiences prior to initial training, and support

\footnotetext{
* Mestranda em Educação pelo PPGEDU/FURG. Licenciada em Educação Física e Bacharel em Ciências Econômicas pela Universidade Federal do Rio Grande

** Doutor em Educação em Ciência pelo PPGEC/FURG. Professor Adjunto do Instituto de Educação da Universidade Federal do Rio Grande.
} 
and marketing provided by the franchise. Also, adhering to the franchise affects the professional performance, as it creates the responsibility to keep up to date and to remain active in the market. At the same time, it benefits the professional with a competitive advantage over the non-franchised and serves a target audience that demands a particular product, the modality sold by the franchise.

Key words: Gymnastics programs. Gym. Initial formation. Physical Education.

\section{PROFESORES DE EDUCACIÓN FÍSICA \\ FRANQUEADOS A PROGRAMAS DE CLASE PRECOREOGRAFIADOS: MOTIVACIONES, RELACIONES CON LA FORMACIÓN INICIAL Y ACTUACIÓN PROFESIONAL}

\section{RESUMEN}

La expansión en el número de centros de acondicionamiento físico en Brasil provocó la aparición de un nuevo producto en el mercado del acondicionamiento físico: franquicias de programas de clases precoreografiadas. Dado este escenario, este trabajo buscó identificar lo que lleva a los maestros de educación física a convertirse en franquiciado, así como discutir posibles interfaces entre su desempeño profesional y la educación inicial. Se llevaron a cabo entrevistas con cinco profesionales de educación física con capacitación, franquiciados de un programa de clase precoreografiado y activo que estaban trabajando en el momento de la investigación. Se concluyó que las principales motivaciones para convertirse en franquiciado son los gustos personales en la danza, como las experiencias socio-corporales previas a la capacitación inicial, y el apoyo y la comercialización que brinda la franquicia. Además, adherirse a la franquicia afecta el desempeño profesional, ya que crea la responsabilidad de mantenerse actualizado y permanecer activo en el mercado. Al mismo tiempo, beneficia al profesional con una ventaja competitiva sobre los no franquiciados y sirve a un público objetivo que exige un producto en particular, la modalidad vendida por la franquicia.

Palabras Clave: Programas de ejercicio. Gimnasio. Formación inicial. Educación Física.

\section{INTRODUÇÃO}

Na sociedade contemporânea, é sensível a profusão de um processo de glorificação do estilo de vida ativo e, simultaneamente, a demonização do sedentarismo em que cada sujeito vem sendo responsabilizado sobre os males que acumula por não se exercitar. (CARVALHO; GOMES; FRAGA, 2015). Essa expansão segue o compasso do crescimento vertiginoso das redes de informação que endereçam a perseguição pela atividade física como sinônimo de saúde e, consequentemente, das instituições de confinamento dos corpos, que funcionam com base nessa promessa. (FRAGA, 2006).

Entre essas instituições está a academia de ginástica que, no Brasil, inicia sob influência da Associação Cristã de Moços (ACM), conhecida, internacionalmente, como Young Men’s Christian Association (YMCA). Segundo Gaio et al. (2010), na década de 70, como resultado dos estudos de Cooper e, na década de 80, impulsionado pelo sucesso dos vídeos de ginástica da atriz norte-americana Jane Fonda, ocorreu a criação 
de uma modalidade ginástica denominada Aerobic Dance (ginástica aeróbica). Tal modalidade levou a um enorme crescimento no número de academias e modalidades de aulas de ginástica pelo mundo. Para Toledo (2010) “[...] a década de 80 é considerada como um período de fertilização das academias de ginástica, assim como do surgimento daquelas de grande porte.

Com a ampliação desses lugares de malhação, assistimos, a partir dos anos 90, o surgimento das franquias que vendem projetos de academias (tanto modelos físicos quanto de gestão, programas e aulas) vinculados a uma marca. Como eco ao crescimento do número de academias de ginástica e de todo um segmento fitness de mercado, a modalidade de ginástica aeróbica novamente veio a se tornar protagonista, como um novo produto a ser consumido, do qual diversas empresas têm se utilizado para vender suas licenças a instrutores interessados nesse tipo de aula. Segundo Flores (2015) “[...] a ginástica, no Brasil, está passando por um processo de privatização de saberes estabelecidos, onde as práticas ginásticas passam a ser de posse de determinadas empresas, que 'criam' padrões de treinamento e o negociam em sua totalidade". (p.43).

A adesão às franquias de programas de aulas pré-coreografadas é um tema inquietante, pois parece ser uma das possíveis justificativas para o aumento significativo desse tipo de modalidade pelo mundo. Ao anunciarem a disponibilização de um pacote de aulas prontas, via um suporte criativo e metodológico, tais empresas afiançam facilitar a vida do professor de Educação Física, que delas se utiliza frente a uma jornada de trabalho cada vez mais intensa.

Nesse sentido, esta investigação pretendeu identificar o que leva um professor de Educação Física a se franquear em empresas que ofertam programas de aulas pré-coreografadas e discutir possíveis interfaces entre sua atuação profissional como franqueado e a formação inicial.

\section{CAMINHOS METODOLÓGICOS}

A pesquisa seguiu uma proposta qualitativa que, segundo Gerhardt e Silveira (2009), preocupa-se com a compreensão de um grupo social, em que o resultado é imprevisível, pois os dados analisados não se submetem à prova de fatos, "são não-métricos (suscitados e de interação) e se valem de diferentes abordagens”. (p. 31).

O conjunto investigado foi composto por cinco profissionais de Educação Física, intencionalmente escolhidos, a partir dos seguintes critérios: a) formação em licenciatura; 
b) franqueados a um programa de aulas pré-coreografadas e c) atuantes com a modalidade a que são franqueados no momento da pesquisa em qualquer espaço não escolar.

Quadro 1 - Síntese das características dos (as) entrevistados (as)

\begin{tabular}{|c|c|c|c|c|}
\hline ENTREVISTADO(A) & IDADE & $\begin{array}{c}\text { ANO DE } \\
\text { CONCLUSÃO DA } \\
\text { GRADUAÇÃO }\end{array}$ & $\begin{array}{c}\text { FRANQUIA COM } \\
\text { A QUAL ATUA }\end{array}$ & $\begin{array}{c}\text { TEMPO DE } \\
\text { FRANQUEADO }\end{array}$ \\
\hline LG & 26 & 2015 & Zumba & 4,5 anos \\
\hline VT & 38 & 2010 & Zumba & 1 ano \\
\hline JP & 34 & 2011 & MIXTURADO & 5 anos \\
\hline TB & 29 & 2011 & Zumba & 6 meses \\
\hline FJ & 24 & 2016 & Fitdance & 1 ano \\
\hline
\end{tabular}

Fonte: Elaborado pelos autores

Como ferramenta para a produção de dados, nos utilizamos de entrevistas semiestruturadas, que, segundo Bêrni (2002), caracterizam-se por: “[...] basear-se em um roteiro que apresenta questões com respostas abertas, não previamente codificadas, nas quais o entrevistado pode discorrer livremente sobre o tema ou pergunta proposta" (p. 241). O roteiro da entrevista foi dividido em três blocos de perguntas, sendo o primeiro correspondente à formação acadêmica e às experiências profissionais; o segundo bloco sobre as motivações, vantagens e desvantagens em se tornar um franqueado; e o último abrangendo as possíveis relações entre a formação acadêmica e a atuação na franquia. As entrevistas foram realizadas entre os meses de maio e junho de $2018^{1}$, nas cidades de Rio Grande e Pelotas, localizadas no sul do Rio Grande do Sul.

Para efeitos de análise, a exploração do material se deu pelo destaque àquilo que atravessou todas as entrevistas, em termos de intensidade narrativa. As recorrências e diferenças foram tratadas em torno de três linhas analíticas: motivações, formação inicial e atuação profissional.

\subsection{Das motivações em ser um franqueado}

Ao analisarmos as entrevistas, nos deparamos com diferentes estímulos, que levaram os profissionais a se tornarem franqueados. Entre eles, aparecem o gosto por dançar, o suporte fornecido e o marketing envolvido na franquia.

\footnotetext{
${ }^{1}$ Todas as entrevistas foram gravadas e tiveram a divulgação de seu conteúdo autorizado pelos entrevistados através da assinatura do Termo de Consentimento Livre e Esclarecido (TCLE), resguardada a identidade nominal.
} 
No que compete ao primeiro fator, não é incomum encontrarmos, no universo da Educação Física, uma rápida associação entre práticas corporais escolhidas pelo professor como repertório da sua atuação profissional e as experiências sociais acumuladas ao longo da vida. Em geral, essa relação é traduzida como gosto, que acaba por si mesmo sendo um argumento legitimador das escolhas que o professor faz. É nessa perspectiva que se encontra a fala de FJ, quando explica o que o levou a aderir ao programa Fitdance, assim que se graduou em Educação Física:

[...] como eu danço desde pequeno eu sempre fiz as coreografias e ensaiei e passava pras minhas amigas e pros meus amigos e a gente dançava em festa; ai quando eu entrei aqui no estúdio a Marisa me mostrou o Fitdance pelo Youtube e falou que ia ter um curso em Porto Alegre e ai ela me motivou e ai como eu já gostava de dançar esse estilo de dança [...] (FJ, 2018).

Segundo Alves (2008), baseado na obra de Pierre Bordieu chamada "A distinção: crítica social do julgamento", o gosto é produto dos condicionamentos aos quais as pessoas foram sujeitadas, ao longo da sua vida. Ele é inculcado pela escola e herdado pela família, e une aqueles em condições parecidas e os diferencia de outros que estejam em campo social diferente.

As falas que demonstravam um gosto oriundo das experiências socioculturais anteriores à adesão a franquia se misturaram a outras, que enfatizavam um gosto de ordem técnica, pois ressaltavam um apreço pela própria metodologia empregada pela franquia. Isso responde a uma segunda motivação revelada para se tornar um franqueado, ou seja, o elogio ao próprio suporte fornecido pela empresa. Foi isso que apareceu na fala de um dos entrevistados, ao mencionar que a adesão à Zumba se deu por ver que "funcionava", em meio a tantas experiências profissionais vividas no espaço da academia:

[...] eu fiquei interessada nisso eu quis conhecer o sistema, aí quando eu conheci ah eu gostei, eu pensei nossa isso funciona, eu quero trabalhar com isso. Dentro de todas as modalidades de dança e de ginástica que eu já trabalhei dentro da academia, e eu trabalho com isso há dez anos, eu vi que foi o que mais funcionou, aí eu pensei 'não, eu quero ser franqueada, eu quero trabalhar com isso (VT, 2018).

Nessa mesma linha, JP relata que durante a graduação, ao conhecer o dono da franquia Mixturado, entusiasmou-se pela "dinâmica" dele. Esse encantamento provocado pelo misto de interesse ao método cativado pela postura e atitude do franqueador, fez com que JP narrasse uma sensação de segurança ao se filiar e adotar a franquia: 
Quando eu estava na graduação eu conheci o dono da franquia onde eu trabalho, eu represento, e eu me apaixonei pela dinâmica dele... ele te dá uma base pra poder trabalhar bem tranquilo e desenvolver muito bem as aulas (JP, 2018).

Em estudo sobre o sistema Body Systems, Brauner (2007) ressalta que a franquia atua não somente fornecendo as coreografias e as músicas, mas também orientando quanto à estratégia a ser utilizada, os métodos, a estrutura da aula e a didática a ser empregada, o que acaba produzindo justamente uma sensação de segurança ao franqueado. Tal modelo de pacote didático também é fornecido pela Zumba, o Fitdance e o Mixturado.

O marketing envolvido nas franquias foi o terceiro e último fator citado como motivação para se tornar franqueado. Esse ponto tem uma ligação muito grande com a necessidade do professor desse tipo de modalidade obter um número maior de alunos. As questões relacionadas à responsabilização do professor pela adesão dos alunos às modalidades oferecidas pelas academias, somadas às constantes inovações oferecidas pelo mercado fitness ${ }^{2}$ acaba fazendo com que o professor de Educação Física esteja sempre buscando algum diferencial para não deixar de ser competitivo no mercado de trabalho. Segundo Pinheiro e Pinheiro (2006, p.9), "as práticas inovadoras alteram as vantagens competitivas, desestabilizando e reconfigurando o mercado até que este alcance um novo estado de equilíbrio, que, por sua vez, será desestabilizado por outra inovação, reiniciando o ciclo".

Em relato, o professor LG coloca que, na metade da sua graduação em Educação Física, já trabalhava com programas de aulas pré-coreografadas. Mas, com o surgimento da Zumba, viu uma possibilidade de atuar com outro tipo de público e abranger um maior mercado profissional:

[...] eu dava aula na época, trabalhava com hip hop nessa academia e aí os colegas fizeram o curso; aí me chamou atenção, vi a aula, e eu já tava afim de trabalhar com uma oficina também diferente pra pegar um público maior além do hip hop, que eu trabalhava mais com crianças e adolescentes, eu queria trabalhar também com o público adulto, então foi uma maneira que eu enxerguei de poder atingir esse público... então o meu interesse foi abrangir um mercado de trabalho maior pra mim $[\ldots]$ (LG, 2018).

Em outra passagem, a professora entrevistada afirma que a procura pelas aulas de franquias, especialmente a Zumba, tornou-se bastante intensa. Não bastava ministrar modalidades nomeadas de ritmos ou similares, o público que frequentava as academias

\footnotetext{
${ }^{2}$ Podemos entender mercado fitness como um termo utilizado para fazer referência a um conglomerado de produtos e serviços criados para acionarem ou atenderem as demandas de um público interessado ou capturado pela busca e manutenção do chamado estilo de vida ativo.
} 
ia atrás daquilo que tinha se tornado uma "febre", o que acabou refletindo na opção por se tornar franqueada:

Eu já dava aula de ritmos na verdade né, e a Zumba agora é uma febre, então acabava que o pessoal procurava a aula de ritmos, dizia que era Zumba, eu explicava que não, não era capacitada, e ai surgiu a oportunidade de fazer o curso, que o curso não é barato e tava bem em conta e eu acabei fazendo assim (TB, 2018).

Com base nesses relatos, percebemos que os profissionais optam por atuar através de franquias de aulas pré-coreografadas. Isso ocorre devido à necessidade de subsídios que consideram complementares à sua formação, por um gosto pessoal ou produzido pelos anseios do próprio mercado que cria e comercializa cada vez mais produtos frutos da metodologia da diversificação das modalidades de ginástica de academia.

A necessidade de atualização, busca por cursos de novas modalidades ou até mesmo por obter uma certificação para atuar com uma determinada marca de um programa faz com que os professores tenham que estar atentos às constantes mudanças que ocorrem no mercado do fitness.

\subsection{A formação acadêmica: relações entre um currículo e a atuação com a modalidade}

A formação em Educação Física segundo Figueiredo (2004) é ampla e pode ser compreendida como aquela que tematiza as atividades corporais nas dimensões culturais, sociais e biológicas. Para a autora, ao moldarem seus currículos através da escolha das disciplinas optativas na formação inicial em Educação Física (que são geralmente "práticas"3), vemos duas correntes de estudantes. A primeira é a dos que seguem um prolongamento das suas experiências sociocorporais anteriores ao curso, motivados pela identificação com a prática e buscando, em alguns casos, ter um bom desempenho acadêmico. Na segunda estão os alunos que partem de motivação contrária, ou seja, escolhem disciplinas as quais não experimentaram anteriormente, demonstrando vontade de aprender algo novo em que gostariam de investir ou trabalhar.

Ao analisarmos os relatos dos entrevistados, verificamos a possibilidade de pensar essas questões por uma terceira via, em que as escolhas de disciplinas são dependentes daquilo que um currículo anuncia, em termos de identificação profissional. No caso em específico,

\footnotetext{
${ }^{3}$ Segundo Figueiredo (2004) as disciplinas ditas pedagógicas não são vistas como práticas pelos estudantes de Educação Física, somente as que se destinam objetivamente a execução de uma atividade da cultura corporal de movimento.
} 
todos os professores afirmam que não tiveram nenhuma experiência com modalidades de aulas pré-coreografadas ou similares durante a graduação, sugerindo uma ideia de lacuna deixada pelo respectivo currículo cursado.

A fala da professora JP justifica esse acontecimento ao fato de seu curso ser uma licenciatura. Ela relata que, somente após a graduação, conseguiu se aperfeiçoar nessa área.

Como era ligado à escola não. A gente teve a ginástica rítmica que é dentro do currículo, a ginástica artística, mas nada que nos estimulasse a isso. Depois da graduação foi que eu busquei me aperfeiçoar nessa área de, de fitness $\operatorname{assim}(J P, 2018)$.

Já o professor LG acrescenta que o protagonismo curricular alcançado pelos esportes na formação inicial, de certa forma, contribuiu para a diminuição de experiências com outras práticas corporais:

[...] a parte da dança na Educação Física foi pouca então se eu não tivesse a minha experiência pessoal com a dança, só a faculdade de Educação Física com certeza não ia ter me dado um, um currículo, uma, um aporte pra mim ministrar uma aula de dança, isso eu posso dizer com certeza, então ai eu me coloco no lugar de outra pessoa que se formou em Educação Física e não tem experiência com dança, é difícil, acho que ai teria tem que realmente buscar uma capacitação a mais (LG, 2018).

É importante salientar que, dentre a amostra de profissionais entrevistados, temos o currículo de três faculdades de Educação Física distintas, que se assemelhavam por nenhuma delas ter proposto uma disciplina sobre modalidades pré-coreografadas. De fato, a escolha de conteúdos componentes de um currículo sempre privilegia um determinado tema em detrimento de outros. Aqueles que exercem o poder de decisão escolhem, validam e legitimam determinados conteúdos e atividades, nos levando a pensar sobre "quem está autorizado a participar dessas decisões, a que interesses servem os conteúdos selecionados, o que é e o que não é considerado conhecimento válido ou importante para a formação das identidades e, por fim, que identidades se pretendem formar". (JR; NEIRA, 2017, p. 3).

Por ser um significativo espaço de atuação profissional, podemos considerar que a supressão do conhecimento pertinente às práticas de academia em determinados currículos de licenciatura restringe não apenas o campo de atuação, mas também o entendimento de que o licenciado não deve ocupar esse universo ${ }^{4}$. Para Batista (2010),

\footnotetext{
${ }^{4}$ A Resolução CNE/CES no 7/2004 encaminhou uma diferenciação à formação em nível superior em Educação Física, apontando uma divisão da graduação em licenciatura e bacharelado. Ainda que explicitamente a resolução não traga em sua redação que a atuação dos licenciados deva se restringir aos espaços escolares deixando os não escolares a cargo dos bacharéis, tais entendimentos foram consolidados desde então.
} 
é preciso buscar vínculos mais orgânicos entre a atuação do professor em academias de ginástica e sua formação. Para tanto, confere aos cursos superiores de Educação Física o objetivo de abordarem as ginásticas de academia como conteúdo disciplinar nos currículos de graduação. O papel do profissional de Educação Física que atua com ginástica de academia é:

[...] situar o problema, determinar metas, escolher meios e teorizar as formas de repensar a realidade, a partir daí, elaborar e buscar novos procedimentos metodológicos. [...] são necessários estudos que venham fundamentar uma proposta pedagógica, como, por exemplo, a anatomia, a neurofisiologia, a biomecânica, a psicologia, a sociologia, a antropologia, a metodologia e a didática, a aprendizagem e o desenvolvimento motor, além da influência dos fatores como a musicalidade, entre outros (BATISTA, 2010, p.454).

A tematização das ginásticas de academia nos cursos de formação inicial poderia resultar também numa compreensão de ginástica que não se confundisse com a noção de dança, algo recorrente a partir das entrevistas realizadas. Em geral, os professores se referem à dança quando perguntados sobre experiências que tiveram durante a graduação com programas de aulas pré-coreografadas.

[...] no curso a gente teve mais a parte assim, uma demonstração né do que seria essas atividades, como aula de ritmos, diferentes tipos de dança que existem, e não foi, não teve uma prática tão, uma prática como posso te dizer, assim, vamos supor, cem por cento voltado a isso (LG, 2018).

Essa ligação, quase que automática, justifica-se devido à utilização da música, da coreografia e alguns passos de dança durante as aulas que remetem a modalidades ginásticas, o que leva muitas pessoas ao entendimento de se tratar de uma aula de dança. Essa situação é alimentada pelas próprias franquias a partir do que anunciam em seus materiais.

A Zumba, por exemplo, em seu manual dispõe que é um programa fitness que se baseia na ginástica com dança. Moreira (2016) ao elaborar estudo sobre o manual da Zumba diz que a relação dela é com a ginástica, que o programa apenas se utiliza da dança para alcançar os objetivos propostos, mas não se caracteriza como uma modalidade de dança propriamente dita.

Já a franquia Mixturado sublinha em seu site que ela é uma aula de dança, e não uma aula de ginástica e que, portanto, qualquer pessoa pode se franquear e ministrar as suas aulas. Na mesma linha segue a franquia Fitdance que em seu site também diz se tratar de um programa de aulas de danças. 
Conforme interpretação da Lei Federal 9.696/1998, que trata, entre outros, das atribuições do profissional de Educação Física, o Tribunal Regional Federal ${ }^{5}$ (TRF $3^{\text {a }}$ Região) entende que aulas de dança não estão sujeitas à fiscalização do Sistema CREF/CONFEF Conselho Regional e Federal de Educação Física -, por se tratar de uma atividade ligada ao campo artístico e cultural. Contrariamente a isso, ser professor de ginástica é uma atribuição exclusiva de quem possui formação em Educação Física. Tal fato nos leva a crer em alguns motivos para que a franquia tanto se preocupe em deixar bem claro se tratar de dança e não de ginástica: a fuga da fiscalização dos conselhos de Educação Física e a possibilidade de abranger mais pessoas como instrutores da franquia devido à dispensabilidade de qualquer formação acadêmica.

Essa referência à dança pode estar permeada também pela necessidade ou estratégia de tornar esse modelo de prática ainda mais popular através do uso de um termo mais institucionalizado, como é a dança.

\subsection{A atuação profissional e a opção pela franquia}

Ao professor de Educação Física, o processo de formação tem continuidade mesmo após estar inserido no mercado de trabalho. A busca permanente por estar conectado às novidades, na verdade, alça-se como condição para que o profissional encontre ou mantenha o seu lugar frente a um mercado de grande concorrência.

Franco et al. (2015), asseveram que segundo a óptica dos proprietários e gestores de academia a responsabilidade da adesão às práticas ofertadas pelas academias é do instrutor: "O instrutor de Fitness possui um papel determinante na manutenção dos clientes no ginásio, podendo também ser uma das causas de abandono” (p. 31). Ao sentir-se unicamente responsável pelo seu número de alunos e faturamento, o profissional atuante com a modalidade franqueada se vê tendo de lançar mão de todas as ferramentas possíveis para obter mais alunos e fidelizá-los. Entre essas ferramentas aparece a franquia que com a promessa de oferecer o suporte e através de todo o marketing envolvido em sua estratégia de divulgação, vem ao encontro do anseio do profissional que vê nela um amparo e uma orientação quanto à formulação da sua aula e de como vendê-la. O professor LG relata que a propaganda da franquia era muito forte, fato que o fez aderir ao programa:

5 Para mais, ver: https://www.conjur.com.br/2017-jul-10/professor-danca-nao-formado-educacao-fisica. Acesso em: 07 jun. 2019. 
Então a propaganda era muito forte em cima e era uma coisa que as pessoas tavam procurando bastante, as pessoas procuravam saber onde é que tinha aula de Zumba e queriam fazer, então por causa dessa, desse marketing em cima (JP, 2018).

Já a professora VT além de citar a repercussão da franquia compara a Zumba a uma aula de ritmos, modalidade com a qual ela já trabalhava, mas se interessou pelo sistema proposto pela franquia.

Bom, quando eu vi que a Zumba, tinha tomado uma repercussão grande assim, que tinha gente trabalhando com Zumba eu pensei, nossa zumba é uma aula de ritmos né e isso eu já faço, só que a Zumba ela tinha um sistema de montagem de coreografias e esse sistema ele trabalhava com, com trabalho aeróbico e de resistência muscular e aí eu fiquei interessada nisso eu quis conhecer o sistema (VT, 2018).

A professora TB conta em seu relato que já tinha um bom número de alunos em suas aulas, mas que ele aumentou em consequência de se tornar franqueada a Zumba. Ela enfatiza o uso do termo "Zumba" como fator determinante para conseguir ampliar a atuação:

[...] não, na verdade as minhas alunas até aumentou assim, depois que eu fiz, mas eu já tinha uma turma bem boa independente de ser a Zumba ou não, é que agora eu uso o nome pra trabalhar mais né, mas eu já tinha uma turma bem boa antes (TB, 2018).

Segundo Magno e Barbosa (2011), como resposta ao enfraquecimento das relações de trabalho, apoiadas em estratégias políticas neoliberais, vemos as mais diversas formas de contratos de trabalho, configurados pela lógica da flexibilização produtiva. Nesse cenário, podemos colocar a figura do franqueado aos programas fitness que, muitas vezes, atua de maneira informal, sem vínculo empregatício e é visto como o único responsável pela sua atualização profissional. Arcar com os custos e se responsabilizar pelo número de alunos, faturamento, marketing e quantidade de vínculos que consegue manter estão na agenda desse profissional permanentemente.

Assim, ele é visto como uma pequena empresa, não possuindo nenhum direito assegurado pelo contratante e que, caso impossibilitado de dar aula ou não demonstre capacidade de fidelizar muitos alunos, é facilmente substituído por outro profissional. Magno e Barbosa (2011) utilizam o termo "empreendedor de si mesmo" para se referir a esse profissional que, ao ser fruto de um sistema que impõem sobre ele toda a responsabilidade pelo sucesso, torna a sua trajetória profissional bastante imprevisível devido à situação de instabilidade que caracteriza as novas formas de emprego. Aderir à franquia passa a ser, então, uma forma de investimento em si a partir da crença de que sua performance ganha valor frente aos não franqueados. Como anunciam em seus sites, 
aderir a elas significa adquirir "aprimoramento", "melhoramento da técnica", tornar-se um "professor de sucesso", valores vendidos como imprescindíveis para o profissional que quer se diferenciar nesse mercado. O contrário disso significa correr o risco de estar defasado ou menos capacitado, desconectado a uma demanda de público e daquilo que os proprietários de academia procuram.

\section{Considerações Finais}

Neste trabalho, procuramos levantar informações a respeito das motivações que levam os profissionais de Educação Física a aderirem às franquias de programas de aulas pré-coreografadas, bem como identificar as possíveis relações entre as respectivas formações iniciais e as características da atuação profissional. Com base nas entrevistas de cinco professores franqueados concluímos que, entre as principais motivações, estão o gosto por dançar, as experiências sociocorporais anteriores à formação inicial, o suporte fornecido pela franquia, que acaba passando uma sensação de segurança ao profissional que não vivenciou experiências com esse tipo de modalidade na graduação, e o marketing disponibilizado pelas franquias, que acaba por gerar uma demanda do público por este tipo de aula.

Nesta lógica, a adesão acaba sendo vista e valorizada pelo profissional e pelo mercado fitness como um empreendimento sobre si mesmo, como uma forma de buscar uma versão melhor de si, criando uma sensação de estar em vantagem mercadológica em comparação aqueles que optam em não se franquear.

A ausência dos programas de aulas pré-coreografadas no currículo dos cursos de licenciatura em Educação Física nos faz refletir sobre o sentimento de não pertencimento desses profissionais a este campo de atuação. Por outro lado, as academias são espaços educativos, em que o professor lança mão de determinados processos pedagógicos, que têm efeitos nas imagens e nos comportamentos corporais daqueles que lá estão.

Nessa lacuna, expandem-se as franquias com a proposta de oferta de aulas e facilitação do cotidiano do profissional, subjetivando aqueles que a acessam, conduzindo os modos de proceder e, de certa forma, homogeneizando as práticas que ministram. E é justamente isso, por outro lado, que coloca o professor numa posição vulnerável no mercado de trabalho. A não necessidade de repensar, reavaliar ou rever a própria prática diante de um cenário "pausterizado", pode levar a uma rápida substituição desse profissional, num primeiro descontentamento do contratante. 


\section{REFERÊNCIAS}

ALVES, Emiliano R. Pierre Bourdieu: a distinção de um legado de práticas e valores culturais. Sociedade e Estado, v. 23, n. 1, p. 179-184, jan-abr, 2008.

BATISTA et. al. Discussões sobre a Ginástica de Academia no curso de Educação Física: possibilidades de encontro. In: GAIO et. al. A ginástica em questão: Corpo e movimento. São Paulo: Phorte, 2010, 2 ed. p. 445-462.

BÊRNI, Duilio de Avila. Técnicas de pesquisa em economia: transformando curiosidade em conhecimento. São Paulo: Saraiva, 2002.

BRAUNER, Vera Lúcia. Novos sistemas de aulas de ginástica: procedimentos didáticos (?) na formação dos professores. Revista Brasileira de Ciências do Esporte. v. 28, n. 2, janeiro, 2007. p. 211-219.

CARVALHO, Yara; GOMES, Ivan; FRAGA, Alex. Educação física + ciências humanas + saúde. In: STIGGER, Marco Paulo. Educação Física + Humanas. Campinas - SP: Autores Associados, 2015. p. 129-154.

FIGUEIREDO, Zenólia. Formação docente em Educação Física: experiências sociais e relação com o saber. Movimento. v. 10, n. 1, janeiro/abril, 2004. p. 89-111.

FLORES, Amanda. Ginástica em academia: compreensões sobre o planejamento de aulas em Salvador. 2015. 92 f. Dissertação (Mestrado em Educação) Faculdade de Educação, Universidade Federal da Bahia. Salvador. 2015.

FRAGA, Alex Branco. Exercício da informação: governo dos corpos no mercado da vida ativa. Campinas - Sp: Autores Associados, 2006. 185 p.

FRANCO, Susana et al. Preferências dos praticantes acerca do comportamento pedagógico dos instrutores de Zumba. Journal of Sport Pedagogy and Research. v. 1. n. 6, 2015.

GAIO, Roberta et al. A ginástica em questão: corpo e movimento. 2.ed. São Paulo: Phorte, 2010. 487 p.

GERHARDT, Tatiana; SILVEIRA, Denise. Métodos de Pesquisa. Disponível em: <http://www.ufrgs.br/cursopgdr/downloadsSerie/derad005.pdf>. Acesso em: 29 nov. 2017.

JR., Wilson; NEIRA, Marcos. Formação inicial em Educação Física: análises de uma construção curricular. Educação em Foco. v. 22, n. 1, janeiro/abril, 2017. p. 1-32. Acesso em: 26 out. 2018.

MAGNO, Attila; BARBOSA, Silva. O empreendedor de si mesmo e a flexibilização no mundo do trabalho. Revista de Sociologia e Política. v. 19, n. 38, fevereiro, 2011, p. 121-140.

MOREIRA, Aluska. Aproximações ou distanciamentos com a dança a partir da concepção, objetivos e estrutura da aula de Zumba. 2016. 22 f. Artigo (Graduação em Educação Física) Centro de Ciências Biológicas e da Saúde, Universidade Estadual da Paraíba. Paraíba. 2016.

PINHEIRO, Ivan; PINHEIRO, Rodrigo. Organização científica do trabalho reinventa um mercado tradicional: o caso do fitness. RAE-eletrônica. v. 5, n. 2, julho/dezembro, 2006. p. 1-26.

TOLEDO, Eliana. A legitimação da ginástica de academia na modernidade: um estudo da década de 80. 2010. 249 f. Tese (Doutorado em História) Pontifícia Universidade Católica de São Paulo. São Paulo. 2010. 